\title{
细碧岩岩浆成因的最新证据
}

\section{一一北祁连山下古生代辉石细碧玢岩单斜辉石斑 晶中发现原生富钠质岩浆包裹体*}

\author{
夏林折夏祖春** \\ (中国地质科学院西安地质矿产研究所)
}

\section{关谓调细珵岩、单斜辉石、岩浆包裹体}

海相火山岩系的重要组成部分一细碧一角质火山岩组合的成因, 长期以来一直处于争 论之中, 其焦点是钠质的来源问题. 作者等 ${ }^{[4-3]}$ 曾根据在细碧一角琣岩中发现无序-过渡型钠长 石, 以及在石英角岩石英昆中发现原生富钠质岩装包裹体, 证明细碧一角质火山岩极有 可能是从一种富钠、富水的岩浆中结晶产出. 最近, 作者又于甘肃省永登县石灰沟奥陶系辉石 细碧玢岩的单斜辉石玨晶中发现了原生富钠质岩将包裹体,现报道如下.

\section{一、单斜辉石珓昌中的原生岩浆包袁体}

辉石细碧玢岩产于奥陶纪海相火山岩系的下部, 是北祁连山下古生代海相火山岩系的 主要岩石组成之一。岩石具斑状结构, 晶由单斜晖石（顶透辉石一普通辉石）和钠长石 ( $\left(\mathrm{An}_{0.4-0.8} \mathrm{~A} \mathrm{~b}_{99.2-299.4} \mathrm{Or}_{0-0.9}\right)$ 组成. 基质具间粒一间片结构, 钠长石微晶 $\left(\mathrm{An}_{0.6-1.5} \mathrm{Ab}_{98.0-99.4} \mathrm{Or}_{\mathrm{r}_{0-0.1}}\right)$ 构成格架，格架间充填有单斜辉石、绿泥石、针磁铁矿、梮石、白针石、黑硬绿泥石等 (图 1). 单 斜辉石斑晶大小为 $(0.5-1.5) \mathrm{mm} \times(0.1-0.4) \mathrm{mm}$, 部分遭受绿泥石、绿帘石化. 多数单斜辉 石斑晶具正环带结构, 自中心向边缘镁含量降低、铁含量升高. 少数单斜辉石斑晶具反环带结 构 (表 1). 单斜辉石斑晶中含大量演化型原生岩浆包裹体(图 2),大小一般为 $7-30 \mu \mathrm{m}$, 具主 矿物负晶形,包表体充填物由子矿物相(单斜辉石十钝磁铁矿)、残余玻璃相和收缩气泡组成.

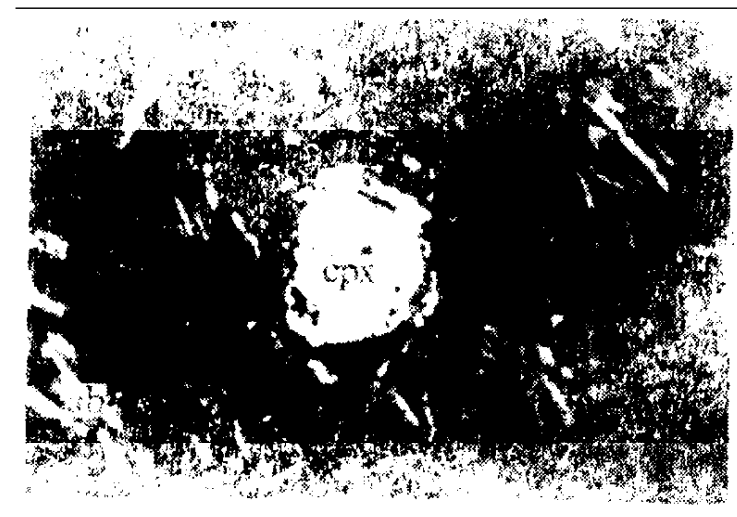

图 1 辉石细㿟玢岩 $c p x-$ 一单科晖石玨晶； $\mathrm{ab}$ 一一钠长石微晶

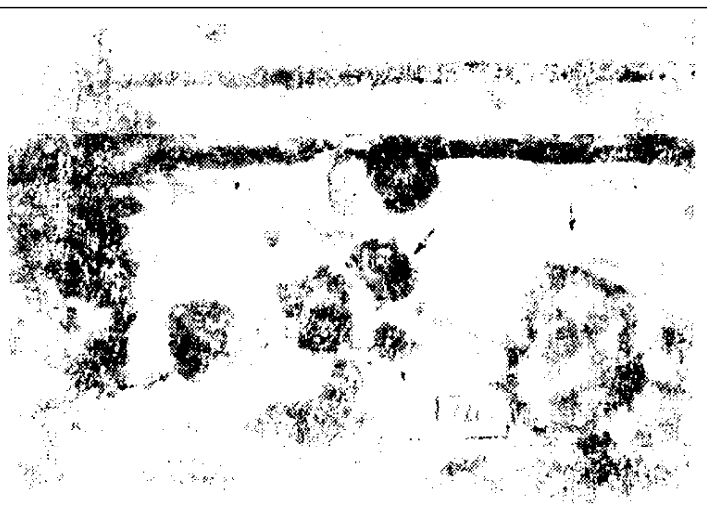

图 2 辉石细碧玢岩单斜晖石轨晶'的演 化㷱岩浆色䆛体(箭头所指)

本文 1988 年 10 月 10 日收到。

* 国家目然科学基金资助项目.

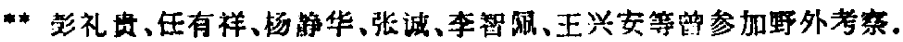




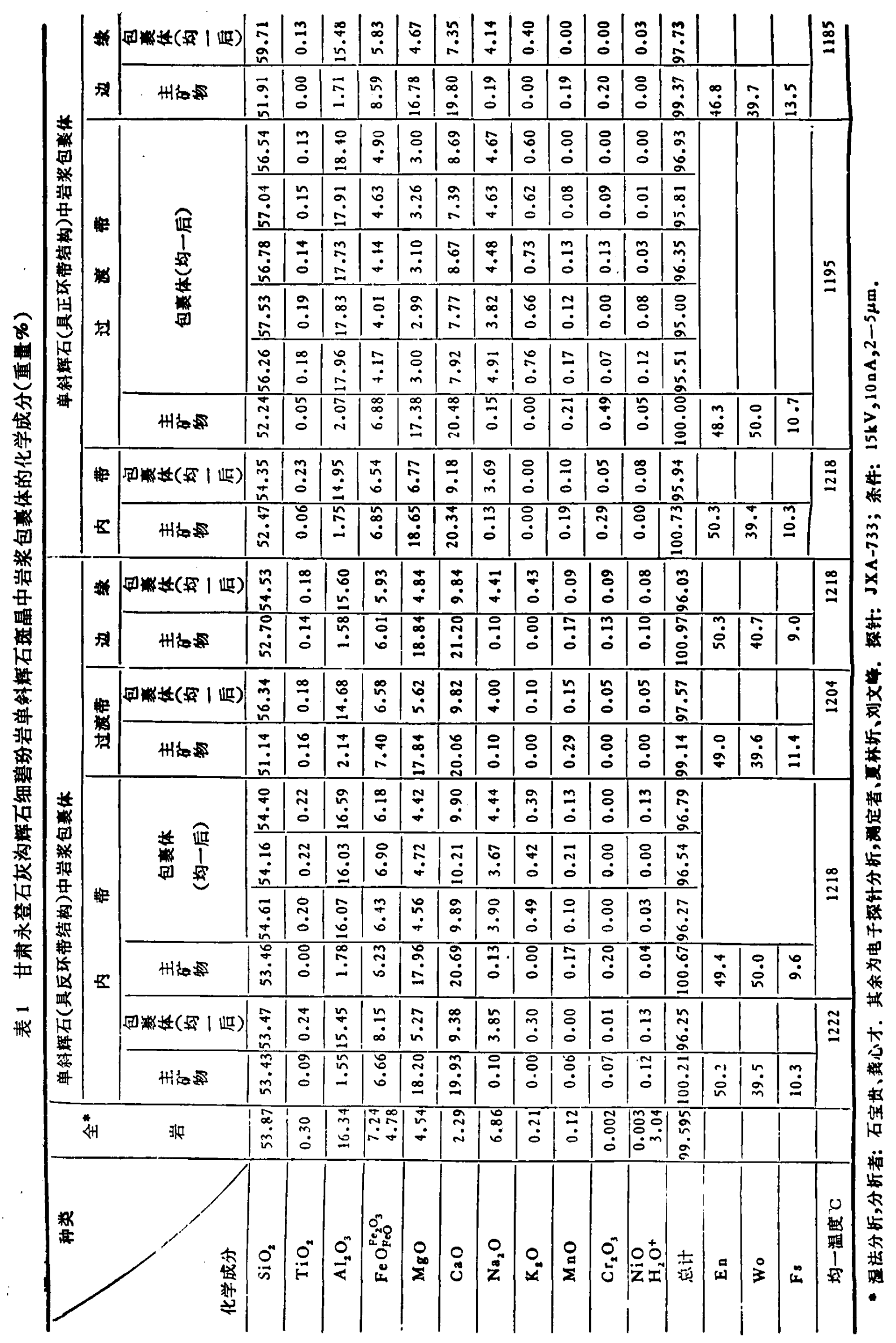


利用 Leitz-1350 型热台进行均一化实验, 自 700\% C 左右, 玻琌相始熔, 子矿物相: 780 $820^{\circ} \mathrm{C}$ 开始熔化,包衰体的均一温度介于 $1185^{\circ} \mathrm{C}$ 至 $1222^{\circ} \mathrm{C}$ 之间. 正环带单斜辉石中, 自中心 向边缘，包䒾体的约一温度逐渐降低 (1218 $\left.\rightarrow 1195 \rightarrow 1185{ }^{\circ} \mathrm{C}\right)$; 反环带单斜辉石中, 自中心向过 渡带,包衰体均一温度降低, 至玨晶基性边缘, 包衰体均一温度复又升高(表 1).于 CHAIXMECA 冷热台中对上述包衰体进行冷冻法研究,查明包衰体的收缩气泡中含有密度为 $0.04 \mathrm{~g} /$ $\mathrm{cm}^{3}$ 的 $\mathrm{CO}_{2}\left(\mathrm{CO}_{2}\right.$ 相 $-28.3^{\circ} \mathrm{C}$ 均一为气相). $\mathrm{CO}_{2}$ 相熔点为 $-54.5^{\circ} \mathrm{C}$, 表明收缩气泡中除 $\mathrm{CO}_{2}$ 外 尚含有其它气体. 将上述 $\mathrm{CO}_{2}$ 密度值及岩浆包衰体的完全均一温度 (1222 ${ }^{\circ} \mathrm{C}$ ) 代人 Bottinga的 $\mathrm{CO}_{2}$ 状态方程 $^{[4]}$ 求得, 单斜辉石晶中心相大约在 $11.5 \mathrm{MPa}$ 的压力下于 $1222^{\circ} \mathrm{C}$ 结晶析出.

\section{二、岩奖包空体的化学成分及其意义}

演化型岩浆包衰体中所存在的玻瑞相只是析出子矿物后剩下的残余熔体, 为了获得单斜 辉石玨晶中演化型岩浆包衰体的初始化学成分, 应将研究样品先均一化, 淬火后再制成探针样 进行测定, 测定结果列于表 1. 从表 1 可以看出, 产于玨晶中心相中的岩浆包衰体基性度最 高, 与全岩化学成分十分相近, 其 $\mathrm{Na}_{2} \mathrm{O}$ 含量为 3.69-4.44\% (重量 \%), $\mathrm{K}_{2} \mathrm{O}$ 含量为 0.00 一 $0.49 \%$ (重量 \%), 这正是细碧岩类的化学成分特点. 由此证明, 辉石细碧玢岩的早期矿物相单 斜辉石结晶时, 周围岩浆已经富钠. 正环带单斜辉石玟晶中, 从中心向边缘, 随着结晶温度逐 渐降低,岩浆包裹体的成分渐趋偏酸性(表 1). 反环带单斜辉石斑晶中, 从内带向过渡带, 随 着结晶温度降低,岩浆包衰体的成分酸度开离; 至富镁贫铁的基性边缘带,结晶温度反向增高, 岩浆包裹体的成分复又变得偏基性, 与内带中岩浆包裹体的成分相近(表 1). 上述事实意味 着细碧玢岩形成过程中,曾发生过岩浆混合作用: 即顽透辉石一普通辉石相首先从早期细碧质 岩浆中结晶, 随着温度降低,岩浆演化程度增高, 变为以普通辉石相为主析出; 尔后, 又有新的、 演化程度低的原始细碧岩浆注人,与先期已发生渖化的中等基性度的岩浆混合, 造成在早期单 斜辉石晶体边部又结晶生长出一圈结晶温度较高的顽透辉石带.

根据电子探针分析不能测出的亏损量可以估算石灰沟奥陶纪细碧质火山岩浆中所溶解的 挥发组分总量 ${ }^{[2.51}$ 为 $2.5-5 \%$ (重量 \%)，其中 $\mathrm{F} 、 \mathrm{Cl} 、 \mathrm{~S}$ 等挥发性元素（S- $-0.87 \%, \mathrm{Cl}$ $0.08 \%, \mathrm{~F}-0.14 \%$,系电子探针分析结果, 用重量 \%表示)所占比例小于 $25 \%$. 考虑到浅部 结晶的基性岩浆中 $\mathrm{CO}_{2}$ 的溶解度一般小于 $1 \%$ (重量 \% $)^{[6]}$, 可以估测, 本区细碧质火山岩浆中 所溶解的 $\mathrm{H}_{2} \mathrm{O}$ 量约为 1.5-3\% (重量\%). 演化型岩浆包裹体中, 除相当部分的 $\mathrm{H}_{2} \mathrm{O}$ 仍溶解 于残余玻琌相中外,由于子矿物的析出, 原来溶解于岩浆中的大部分其它挥发组分均已转移到 收缩气泡之中. 经激光喇曼探针测定, 收缩气泡中的气相组分以 $\mathrm{CO}_{2}$ 为主, 此外还有 $\mathrm{N}_{2} 、 \mathrm{CH}_{4}$ 、 $\mathrm{H}_{2} \mathrm{O} 、 \mathrm{H}_{2} 、 \mathrm{H}_{2} \mathrm{~S} 、 \mathrm{SO}_{2}$ 等(表 2). 根据岩浆包衰体收缩气泡中的气相成分, 以及包衰体的完全均 一温度和均一时的玉力, 可以借助热力学方法 ${ }^{[7]}$ 计算出各气体组分的逸度(表 2) 和单斜辉石 结晶时的氧逸度 $\left(f \mathrm{O}_{2}=10^{-11.02} \mathrm{bar}\right)$ 条件.

综上述, 本研究成果为细碧岩的岩浆成因提供了最新确丵证据. 它至少可证明甘肃省永 登县石灰沟奥陶纪辉石细碧玢岩中的单斜辉石是从一种富钠富水的基性岩浆中结晶析出.

将单斜辉石中岩浆包裹体的化学成分投影于 Miyashiro ${ }^{[8]}$ 的火山岩系列分类图中(图 3)， 可以判别该区细碧岩类的“源”岩浆系列应属于岛弧型钻碱性火山岩系列. 至于该区富钠质的 细碧岩浆是否是正常的湴碱性岩浆的分异派生物, 或是钙碱性火山岩浆在上开过程中与海底 沉积物中的热卤水发生岩浆混染作用所产生 ${ }^{[9]}$ ? 尚需进一步研究. 目前看来, Soler ${ }^{[10]}$ 根据西 


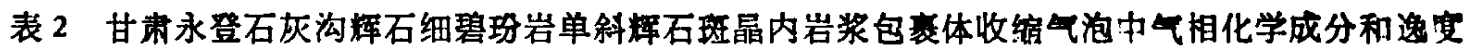

\begin{tabular}{|c|c|c|c|c|c|c|c|c|c|c|c|c|c|c|c|c|}
\hline \multirow{2}{*}{$\begin{array}{l}\text { Th } \\
{ }^{\circ} \mathrm{C}\end{array}$} & \multirow{2}{*}{$\begin{array}{r}\mathrm{P}_{\mathrm{Q}} \\
\mathrm{MPa}\end{array}$} & \multicolumn{7}{|c|}{ 气相成分（mol\%） } & \multicolumn{8}{|c|}{ 气体组分的速 (ber) } \\
\hline & & $\mathrm{CO}_{2}$ & $\mathbf{N}_{\mathbf{z}}$ & $\mathrm{CH}_{\text {. }}$ & $\mathrm{H}_{2} \mathrm{O}$ & $\mathbf{H}_{2}$ & $\mathrm{H}_{2} \mathrm{~S}$ & $\mathrm{SO}_{2}$ & $\mathrm{tO}_{2}$ & $\mathrm{COO}_{2}$ & $f \mathbf{N}_{2}$ & $\mathrm{fCH}_{4}$ & $f \mathrm{H}_{2} \mathrm{O}$ & $\mathrm{fH}_{2}$ & $f \mathrm{H}_{2} \mathrm{~s}$ & $\mathrm{SSO}_{2}$ \\
\hline 1222 & 11.5 & 60.4 & 4.8 & 6.4 & 8.4 & 3.4 & 7.9 & 8.7 & $10^{-11.02}$ & $10^{1.06}$ & $10^{0.10}$ & $10^{0.82}$ & $10^{0.09}$ & $10^{0.60}$ & $10^{0.27}$ & $10^{1.01}$ \\
\hline
\end{tabular}

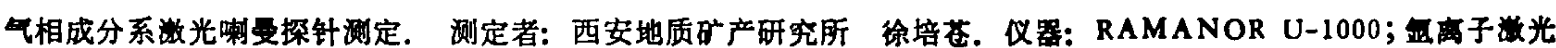

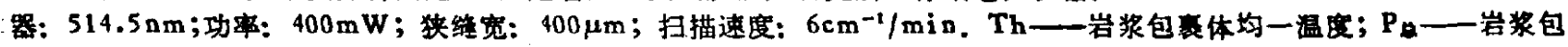
体均一时的医力, 系根据收缩気泡中 $\mathrm{CO}_{2}$ 的密度和均一温度计算求得.

班牙 Huelva 地区细碧岩类氢-氧同位素研究数据所提出的有关细碧-角斑岩形成的 “海底热 卤水-岩浆混染”成因模式比较有说服力.
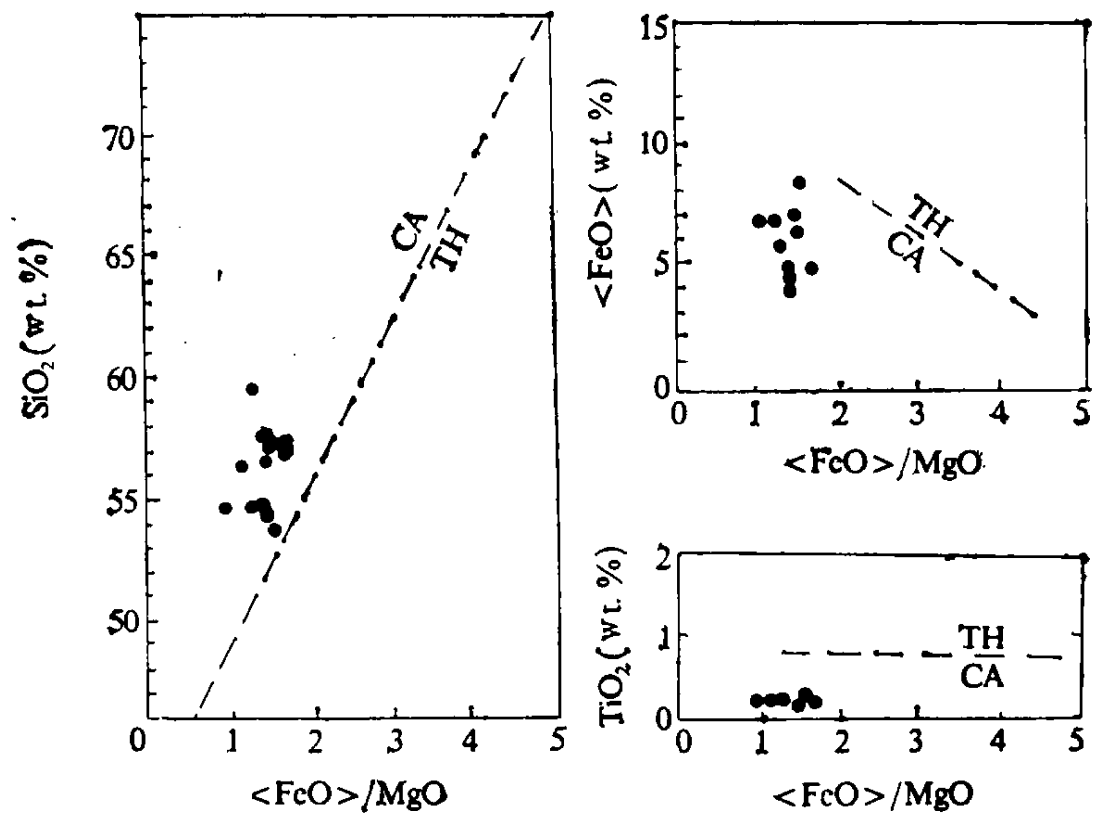

图 3 火山岩系列分类图(据 Miyash1ro，1975)

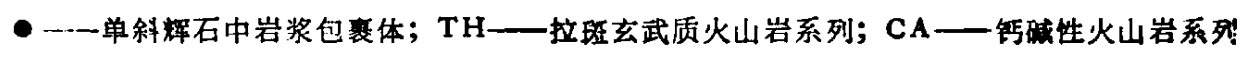

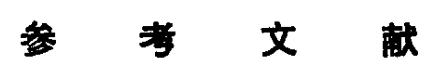

[1] 夏林所、黄月华,地球化学, 1979,1: 13-27.

[2] Xia Linqi (夏林折), Thèse de doctorat, Universite de Paris sud, 1984,316.

[3] 夏林圻,岩石学报, 1987,2: 51-63.

[4] Bottinga, Y, and Richet, P., Amer. J. Sci., 281(1981), 615-660.

[5] 夏林圻,岩石矿物学杂志,7(1988), 1: 1-11.

[6] Mysen, B. O. et al., Amer. J. Sci., 276(1976), 455-479.

[7] Булах А. Г. и Кривовичев В. Г., Расчет Минеральных Равновесий, 1985,183.

[8] Miyashiro, A., J. Geol., 83(1975), 249-281.

[9]而林圻、夏祖春, 中国地质科学院西安地质矿产研究所所刊, 1987, 19: 1-30.

[10] Soler, B., C. N.R. S., Nancy, 1980,461. 